\title{
A QUESTÃO DA REPRESENTAÇÃO FEMININA NOS CARTAZES SOVIÉTICOS - ALGUMAS QUESTÕES
}

\section{THE QUESTION OF REPRESENTATION OF WOMEN IN SOVIET POSTERS - SOME QUESTIONS}

\author{
Thaiz Carvalho SENNA ${ }^{1}$
}

\begin{abstract}
Resumo: O presente artigo aborda a questão da propaganda soviética, especialmente os cartazes de propaganda em que é representada a figura feminina. Em um primeiro momento, contextualizaremos a questão feminina na Rússia Soviética; em um segundo, trataremos da questão da representação nos cartazes; finalmente, em um terceiro, abordaremos as principais conclusões, fruto de nossa análise acerca do tema.

Palavras-chave: História da Rússia; Propaganda Soviética; História das Mulheres

Abstract: This article addresses the issue of Soviet propaganda, especially the propaganda posters in which the female figure is represented. At first, we contextualize the women's issue in Soviet Russia; After, we deal with the question of representation on posters; Finally, we approach the main conclusions, results of our analysis on the subject.
\end{abstract}

Keywords: Russian history; Soviet propaganda; Women Históry.

Com o "ruído infernal das máquinas da oficina e da sirene das fábricas" nasce a mulher moderna. É assim que a revolucionária russa Aleksandra Kollontai constata, em seu livro A Nova Mulher (KOLLONTAI, 1978 [1918], p.13), o fenômeno que se abate sobre o "segundo sexo" em considerável parte do mundo.

Apesar de partir de um aspecto econômico - a entrada em massa das mulheres na classe trabalhadora - a nova mulher de Kollontai compreende transformações profundas com relação à personalidade feminina. Chamado pela autora de celibatário ${ }^{\mathrm{i}}$, esse novo tipo de mulher é caracterizado pela liberdade frente às necessidades que antes a prendiam ao lar e pela independência frente aos sujeitos que antes a sujeitavam. Em última instância, as mulheres modernas podiam (ao contrário das antigas) escolher não casar e não ter filhos ii . Isso se dava com o trabalho não-doméstico, que lhes garantia autonomia. Essa autonomia era conquistada não apenas por meio do salário, mas também por meio do contato que as mulheres tinham com o novo mundo que a elas se apresentava - inclusive pela convivência com as outras mulheres trabalhadoras, que poderiam entre si trocar experiências e

\footnotetext{
${ }^{1}$ Doutoranda em História Política e Social - Programa de Pós-graduação em História - Departamento de História - Niterói, RJ - Brasil. Graduanda em Letras - Faculdade de Letras - UFF - Universidade Federal Fluminense, RJ. Participante bolsista do Laboratório de Estudos de Tradução da UFF - Equipe de Língua Russa - Orientadora Ekaterina Vólkova Américo. Email: thaizsenna@gmail.com
} 
organizar-se: "[com a entrada da mulher no mercado de trabalho,] ao mesmo tempo em que se desenvolve a consciência da sua personalidade e dos seus direitos, nasce e evolui, na mulher operária, um novo tipo de sentimento de coletividade: o sentimento de companheirismo" (KOLLONTAI, 1978, p.18). Concomitantemente, se não viviam na dependência de um marido que as mantinham, as mulheres do tipo celibatária contavam apenas com suas próprias forças para lutar por sua subsistência. (KOLLONTAI, ibidem, p.14). Deviam, portanto, submeter-se à exploração capitalista, a fim de vender sua força de trabalho. Essa é a dialética do duplo caráter da entrada em massa da mulher no mercado de trabalho, apontada por Kollontai:

As relações de produção, que durante tantos anos mantiveram a mulher fechada em casa e submetida ao marido, que a sustentava, são as mesmas que, ao arrancar as correntes enferrujadas que aprisionavam, impelem a mulher frágil e inadaptada à luta do quotidiano e a submetem à dependência do capital (KOLLONTAI, 1978, p. 14).

Após a revolução soviética, a mesma militante que prevê a possibilidade de as mulheres se organizarem entre si, posto que exerciam juntas a atividade laboral, torna-se uma das líderes da maior prova de que sua previsão tinha fundamento: em 1919, é criado o Jenotdel, o departamento de mulheres do Partido Comunista. Tal departamento era uma política do Partido que constituía, conforme nossa hipótese $e^{\mathrm{iii}}$, a síntese da importância dada às - e conquistada pelas - mulheres. Essas, entendidas como metade da força motora que consolidaria a revolução socialista - econômica e socialmente - deveriam aderir à causa comunista e ao trabalho não doméstico. O Jenotdel objetivava, assim, alcançar a emancipação feminina - o que significava, para tal departamento, que a antiga mulher (supersticiosa, religiosa, submissa, despolitizada, analfabeta, não comunista) virasse uma Nova Mulher, nos termos caracterizados por Kollontai.

Essa demanda não era apenas da jovem revolucionária. Herdeiros de todo o contexto de lutas em prol da emancipação feminina, os partidários do Partido Comunista também compreendiam tal necessidade, tal como Inessa Armand ou Nádjeda Krúpskaia. À época da revolução, podemos citar Vladímir Lênin - famoso dirigente partidário do Partido Comunista e marido de Krúpskaia - como um dos militantes homens mais avançados em relação à igualdade de gênero. Em 1903, ele foi o responsável pela introdução, no esboço do Programa do Partido Operário Socialdemocrata Russo, das reivindicações pelo "sufrágio

Página $\mid 104$

História e Cultura, Franca, v. 6, n. 1, p. 103-125, mar. 2017. 
universal, igual e direto" para ambos os sexos, pela "abolição de todos os estamentos e plena igualdade de direitos a todos os cidadãos independentemente do sexo, da religião ou da raça", pela "proibição do trabalho da mulher nos ramos em que é especialmente prejudicial para o organismo feminismo" e pela proteção à maternidade (incluindo 10 semanas de licença maternidade, creches nos locais de trabalho e a criação de postos de mulheres inspetoras) (LENIN, V. Sobre a emancipação da mulher. Apud ANDRADE, 2015, p.174).

Em abril de 1917, afirmou o líder do partido: "Enquanto as mulheres não forem chamadas a participar livremente da vida pública em geral, cumprindo também as obrigações de um serviço cívico permanente e universal, não pode haver socialismo, nem sequer democracia integral e durável” (LENIN, 1947). Lenin considerava nessa fala a profunda necessidade de contar com as mulheres para construir uma sociedade da qual elas eram quantitativamente parte considerável. Sair do ambiente doméstico, ao qual estavam ligadas há séculos, e participar de discussões, compartilhar situações, formular ideias, decidir questões políticas e sociais era um salto qualitativo quanto à emancipação feminina - e algo que deveria ser, para Lênin, encorajado pelo Partido. Podemos adiantar que, para muitas mulheres, esse cenário foi de fato uma realidade, graças ao esforço da organização partidária e, mais especificamente, do Jenotdel. O líder bolchevique contrapõe, ainda, o mesmo direito político a obrigações civis. A mulher é, então, na concepção leninista, um indivíduo que, tal como o homem, deve servir à construção do sistema socialista, realizando atividades políticas, sociais e laborais.

Dessa forma, podemos pensar, também, com Lênin, a dupla face das razões das mulheres estarem, de forma consideravelmente maior que antes, presentes no mercado de trabalho. Por um lado, isso era um direito, fruto das lutas feministas que reivindicavam que as mulheres ocupassem também esse espaço, tanto na Rússia, quanto no mundo, e que fazia objeções à saída feminina do ambiente doméstico para o laboral, algo extremamente reacionário, sendo necessário, então, travar um combate constante para que mais e mais mulheres adentrassem nessas atividades. Por outro, entende-se também que o labor profissional era uma tarefa que o próprio capitalismo avançado impunha às mulheres. Assim, dado o nível de desenvolvimento das forças produtivas, não era mais possível que metade da população mundial não participasse da produção de riquezas. Sendo as mulheres, então, estruturalmente necessárias ao desenvolvimento econômico - mesmo em uma 
sociedade não capitalista como a que se instaurava - Lênin percebia que a não participação desse gênero na vida produtiva laboral levaria um sistema, mesmo o socialista, ao fracasso. Tal labor constitui, então, uma obrigação não apenas para as novas mulheres, como também para o Partido Comunista, em termos de colaborar para que assim o fosse.

Os mesmos militantes herdeiros das reivindicações de igualdade entre homens e mulheres, no entanto, eram, também, contraditoriamente, herdeiros de séculos de discursos e práticas que propunham a superioridade masculina, a violência contra a mulher, o reforço do homem como pai de família, a anulação da mulher como ser humano e o ambiente político negado às cidadãs femininas. O paternalismo religioso, legislativo e social, propagava-se cotidianamente em sua face política, também nos movimentos libertários russos, nos quais podemos incluir, sem temer, o posterior Partido Comunista. Isso se dava, por um lado, nas justificativas para não haver políticas partidárias específicas para as mulheres. Até 1917, a opinião majoritária no Partido - contra qual Kollontai lutou - davase por duas vias convergentes: a de que, caso houvesse qualquer tipo de especificação, como o feminismo, perder-se-ia de vista o aspecto classista, necessário ao Partido; e a de que, caso as mulheres obtivessem ganhos nessa estrutura, elas trairiam a própria classe, inclinando-se para o liberalismo burguês (WOOD, 1997, p.30).

Tais visões - responsáveis em parte pelo não aumento de mulheres no Partido eram defendidas inclusive pelas próprias militantes mulheres. Esse fenômeno - a opressão à mulher - era uma metonímia do que ocorria em toda a sociedade, possivelmente de forma ainda mais acentuada, por não haver diálogos mais aprofundados com posições contrárias, como às que se dedicou Kollontai. A líder feminista, assim, expõe a nova mulher enquanto fenômeno constatado, baseada em uma dada materialidade, visto que sujeitos com as características designadas já se faziam presentes de forma considerável na sociedade. Ao mesmo tempo, entendemos que a autora considera o movimento desigual e combinado a que os aspectos estão submetidos na sociedade russa. Dessa forma, as atitudes e a psicologia da "antiga" mulher podem estar encarnadas em diversas delas, não apenas nas que ainda não adentraram no mercado de trabalho, mas também nas que nele já se faziam presentes. A "nova" mulher estava, portanto, lado a lado com velhas ideologias. A consciência, apesar de provir também da materialidade das atividades cotidianas, fazia-se, assim, significativamente fluida. 
Ao compreender essa contradição, o PC investiu, então, em transformar toda a população feminina soviética no conjunto das mulheres celibatárias, emancipadas, trabalhadoras, comunistas. Essa mulher futura idealizada será então vista como personagem nos cartazes de propaganda, como cidadã nas novas legislações, como parte do povo a ser pensado nas diversas políticas públicas e partidárias do PC.

Dessa postura pró-emancipação decorreram inúmeras transformações na sociedade socialista com relação às mulheres. Das mais básicas, já realizadas pelas potências capitalistas à época da revolução, às mais inovadoras, que só puderam existir no âmbito de um Estado operário, as mulheres da sociedade soviética tiveram suas vidas mudadas não apenas enquanto pessoas em um sistema completamente diferente do anterior, mas, também, quanto às suas tarefas, suas possibilidades, sua imagem, seu lugar na sociedade e na história. Se, anteriormente, como coloca o historiador britânico Hobsbawm, as mulheres não estavam fora da história, mas fora da história da sociedade do século XIX (HOBSBAWM, 1988, p.277), no início do XX, elas foram convocadas a ser uma das protagonistas não apenas das mudanças no corpo social, mas da sua própria história. Como frisa Kollontai, a mulher, "de objeto da tragédia masculina, converte-se em sujeito da sua própria tragédia" (KOLLONTAI, 1978, p.22).

Podemos considerar como um marco nesse processo a ultrapassagem da lei tsarista que pregava a inferioridade feminina diante do homem (como citado por GOLDMAN, 2014 e WOOD, 1997). As primeiras leis soviéticas, rompendo com essa premissa, colocavam a mulher, enfim, como ser humano, tal como seus pares masculinos. Militantes como Kollontai e Lenin não acreditavam que a igualdade formal bastava para que houvesse igualdade de fato - tanto no que dizia respeito aos direitos historicamente negados ao sexo feminino, ou ao que era relativo à opressão historicamente legada a esse grupo, quanto no que concernia às barreiras objetivas e subjetivas à entrada do mesmo no mercado de trabalho e no Partido Comunista. Assim, foi necessário não apenas eliminar as leis explicitamente retrógradas da antiga legislação, como criar novas leis que favorecessem a colocação da mulher no novo patamar, equiparando-o ao homem, considerando o lugar social privilegiado que esse já detinha historicamente.

Ainda que chegassem ao âmbito prático, os decretos e leis, porém, não bastavam. Uma sociedade não seria convencida de mudanças tão profundas em seu cotidiano apenas com o texto escrito. Os problemas tinham suas raízes fincadas em instituições e práticas 
sociais que ultrapassavam os mecanismos legais. Indicar à mulher que ela deveria cumprir funções políticas, participando ativamente do corpo social, por exemplo, não significava muito se ela, primeiro, tinha que continuar realizando as tarefas domésticas e cuidando da prole $^{\mathrm{iv}}$; segundo, se ela não tinha educação o suficiente para exercer a maioria das funções que uma sociedade industrializada requer; e terceiro, se ela não era convencida de que sua emancipação era uma possibilidade, posto que historicamente fora oprimida para permanecer submissa e apenas no âmbito doméstico. Assim, o PC tentou solucionar isso com a criação de instituições públicas e gratuitas, como restaurantes e creches, criou escolas e investiu em literatura, grupos de leitura, etc., bem como em propaganda na qual constava a mulher como figura pública e política, a fim de convencê-la que também ela poderia ocupar aquele lugar.

É inegável que o período a partir da Revolução Socialista e, principalmente, a partir de 1919 (podendo a criação do Jenotdel ser considerada tanto uma prova quanto um impulso a isso) concentrou uma enorme atenção do Partido e da sociedade política quanto às mulheres. Mulheres essas que antes jaziam em condições muito piores do que as dos outros Estados europeus, dada a natureza misógina e retrógrada do regime monárquico tsarista; que não foram diversos direitos já adquiridos há anos em outros países; que tinham chicotes em seus leitos, para que o marido a castigasse, se assim desejadov; que estavam entranhadas em lógicas religiosas e legais que a julgavam inferior; que ouviram "então vamos fazer uma reunião só para homens!" (como visto em WOOD, 1997, p.32), ao querer se organizar para lutar contra tudo isso.

Foram essas mesmas mulheres que saíram de condições extremamente antiquadas para outras que, em diversos casos, eram muito mais avançadas do que as em que se encontravam suas irmãs do mundo capitalista: legalização do aborto, casamento civil, divórcio direto, direito ao voto, salário igual, proteção à maternidade, pensão alimentícia; conquistas que estavam longe de serem alcançadas na maioria dos países. Algumas delas, que em nenhum deles ainda havia ocorrido. Outras, ainda, que em muitos países do corrente século XXI ainda não tinham sequer sido discutidas. Tudo isso para mulheres que haviam acabado de sair de uma sociedade que praticamente as escravizava.

A postura libertária do Partido Comunista, contudo, não escaparia às contradições de sua época, das permanências de tempos anteriores, ou mesmo, do domínio majoritário do gênero masculino. Primeiramente é importante dizer que os saltos progressivos da 
história não se dão no vácuo, tendo suas raízes na própria sociedade, no modo pelo qual foi feita pela história (NOVACK, 2008, p.70). Não é possível, assim, que um sistema possa pular etapas, que social e historicamente estão dadas de determinada forma, sem que haja contradições estruturais nos resultados. Como nos lembra Hobsbawm (HOBSBAWM, 1997, p.343), revoluções são fenômenos que abrem as maiores possibilidades para que haja grandes transformações em um curto espaço de tempo. Em uma sociedade como a Rússia que, em 1917, reproduzia não os mecanismos produtivos, sociais e culturais do capitalismo avançado, mas, sim, os de uma monarquia autoritária com uma burguesia frágil e marginalizada que, ao invés de adentrar nesse capitalismo, fazendo uma revolução burguesa - como fez a maior parte dos países europeus - saltou para um nível mais avançado, realizando uma revolução socialista, essas contradições, mais do que intrínsecas, eram fundantes. No caso da questão das mulheres, o mesmo se deu. Como coloca Kollontai, "somente as frescas tempestades revolucionárias são fortes o bastante para varrer velhos preconceitos contra a mulher e somente as pessoas com trabalho produtivo podem igualar e libertar completamente a mulher, construindo uma sociedade nova" (KOLLONTAI, 2007, p.80)

Uma das mais profundas e disseminadas contradições na sociedade socialista que iremos tratar é comum em todos os Estados ocidentais e, se deixou de ser em algum país, não foi por muito tempo ${ }^{\text {vi. }}$ o lugar da mulher enquanto mãe e dona-de-casa. Mesmo um Estado Operário com estruturas avançadas que objetivavam mostrar os novos papeis possíveis às mulheres, colocando-as em situação de igualdade com os homens, não era possível livrar-se do elemento retrógrado e pouco igualitário de entender a mulher como a responsável praticamente única por realizar as tarefas de casa e de cuidar da prole - ideias e práticas essas que remetem a uma estrutura sequer capitalista, mas pré-capitalista (ver REED, 1969) - ao invés de serem consideradas humanas livres dessas tarefas, tal como os homens o eram ${ }^{\text {vii }}$.

“Dê-nos uma nova existência!'viii : a nova vida representada em cartazes de propaganda

A propaganda partidária foi uma das estratégias mais definidoras do processo de convencimento da população quanto ao novo que estava sendo estabelecido. Por se distinguir totalmente do regime anterior, o tsarismo, bem como das outras alternativas 
políticas desenvolvidas no mundo, o Estado Soviético precisou, por um lado, apresentar as novas ideologias para o povo; por outro, convencê-lo com relação a elas, a fim de transformar a consciência e as práticas das pessoas e se legitimar como força política, mantendo seu poder.

A política da propaganda comunista funcionava, ao que entendemos, como uma tentativa de contra-força em relação aos resquícios do regime anterior. A postura de, mesmo após a revolução, continuar lutando contra determinados aspectos do passado relacionava-se à teoria da revolução permanente de Trótski ${ }^{\text {ix }}$ que, segundo Novack, era produto da própria teoria do desenvolvimento desigual e combinado. A propaganda partidária parecia se comportar como alinhada com ambas as teorias, justamente por ser um mecanismo que considerava que não foi porque ocorreu a revolução socialista que tudo irá mudar automaticamente. Era, pois, nesse sentido, dialética e não-etapista. Sintetiza Novack:

(...) a revolução socialista vitoriosa não erradica igualmente e de repente todas as relações e costumes do passado, senão que só elimina aquelas instituições econômicas, políticas e legais que são a raiz da dominação capitalista. Depois da conquista do poder, a revolução operário-camponesa está obrigada a atacar e eliminar toda a obsolescência herdada, tão rapidamente quanto seja permitido pelas condições objetivas (NOVACK, 2008, p.87).

A União Soviética durou quase um século. É possível inferir que a propaganda soviética teve sucesso considerável quanto à luta contra toda a obsolescência herdada - na qual ela, ao mesmo tempo, baseou-se, claramente unida a outros mecanismos como a agitação, a formação, etc. ${ }^{\mathrm{x}}$

Essa estratégia partidária tinha algumas especificações positivas frente a outros formatos. A Rússia era em grande parte analfabeta e esse fenômeno incidia de forma ainda mais intensa sobre o sexo feminino. Cartazes vivazes, com formas simplificadas e com pouco ou nenhum conteúdo escrito - que por vezes apenas praticamente só ratificava a imagem (apesar de cada vez mais aperfeiçoados artística e politicamente), estéticas baseadas em gêneros da antiga tradição popular russa (como os Lubók), conseguiam dialogar de maneira impactante e generalizada com a população que era, em geral, analfabeta. Como acentua Krúpskaia, sobre a questão pedagógica contida nos cartazes, em relação à maior parte da população, os camponeses: 
Para o presente e para o futuro próximo, um camponês pode aprender a melhorar a sua produção apenas se ele é ensinado por exemplo visual. E, em geral, o camponês, assim como os trabalhadores em massa, pensam muito mais em termos de imagens do que fórmulas abstratas; a ilustração visual, mesmo quando um alto nível de alfabetização é atingido, sempre desempenhará um papel importante para o camponês (KRÚPSKAIA, N. Pedagogicheskie sochineniia $v$ desiati tomakh: 1959, apud BONNELL, 1997, p.5).

As visões de mundo são tão potentes e tão enraizadas na sociedade que, mesmo sendo fruto de modos de produção, permanecem por meio de diversos aspectos. Mais do que isso, os próprios modos de produção novos, ainda que novos, são imersos em contradições. Assim, ainda que seu lugar fosse de vanguarda e estivessem cumprindo a dita tarefa de atacar a herança, também os produtores das propagandas e demais membros do PC eram perpassados pelas mesmas, possuindo, em conjunto e individualmente, ideias e estruturas próprias de um sistema que, no geral, não mais existia.

Ainda assim, esse cenário em muito se contrasta ao que ocorrerá posteriormente, já que o Estado repreenderá os artistas que não seguirem suas linhas artísticas. Em 1930, como parte da reorganização geral das sessões para maior controle do governo, processo que também extinguiu o Jenotdel, as funções do Tsentropechat, agência central de distribuição de imprensa, foram assumidas pelo Soiuzpechat, uma agência de mesmo tipo, mas controlada diretamente pelo governo, o que representou a tomada, por esse, do poder de decisão sobre a arte. Isso se legitima com maior intensidade em 1931, quando a produção de cartazes fica sob a supervisão do Departamento de Arte do Estado e, especialmente, em 1932, quando ocorre o $1^{\circ}$ Congresso dos Escritores Soviéticos, que institucionaliza o realismo soviético - estilo artístico oficial, adotado como política do Estado para a estética, que abarcava todos os campos da arte - cartazes, literatura, cinema, pintura, arquitetura, etc - e pregava que "O artista não só retrata nossa construção socialista de verdade, mas também, toma parte ativa nele próprio" (MP Arkad'ev, 'Smotr sovetskogo IZO-iskusstva', Chudozhniki RSFSR apud GULDBERG,1990). A partir de então, os artistas só poderiam produzir arte que contivesse estes quatro aspectos: o proletário, uma arte que fosse relevante para os trabalhadores e compreensível para eles; o típico, com cenas da vida cotidiana das pessoas; o realista, no sentido da representação; e o partisan, que significava apoiar os objetivos do Estado e do Partido. Em síntese, a partir dessa decisão, os artistas estavam no campo oposto ao da liberdade, tendo que tomar apenas a 
verdade do governo para sua arte. Dos que isso não cumprem, muitos são exilados, outros são mortos. A trágica quantidade de suicídios de artistas que há no final da década de 1920 e início de 1930 é bastante representativa do problema.

Parte significativa dos cartazes de propaganda debruça-se sobre as questões femininas - isto é, consideradas e colocadas como femininas - transformando a mulher trabalhadora em, ao mesmo tempo, público e representação. Até o fim da década de 1920, é possível perceber as inovações na forma de tratar politicamente e representar a mulher, visando sua emancipação, retirando-a de suas funções tradicionais e dando-lhe igualdade. Durante a década de 1920, o governo de Stálin ainda não estava consolidado, tampouco o estava o realismo soviético. Assim, determinados aspectos relacionados às mulheres - que, após tais fenômenos, estiveram explícitos na sociedade - ou não apareciam, ou eram colocados de outras formas. Essas formas mais implícitas ou eufêmicas são capazes de demonstrar onde se situavam os limites da representação da mulher como igual ao homem - isso é, até que ponto a igualdade de gênero poderia existir, pois, como colocamos anteriormente, houve aspectos que nem os cartazes nem as políticas públicas conseguiram dar conta.

Assim, apesar da ampla diversidade artística pré-1931, própria do contexto revolucionário, a análise dos cartazes justifica-se, pois, como afirma a própria Bonnell, houve "notável consistência na criação e disseminação de certas representações iconográficas.” (BONNELL, 1997, p.11.) - e é a partir das consistências, inconsistências, insistências e contradições que tentaremos realizar a nossa análise, no que tange à relação do Estado e da sociedade como um todo sobre a representação feminina, especialmente, à medida que isso perpassa diretamente pela construção social da Nova Mulher.

A representação da mulher que o Partido idealizava não era criada no vácuo. Era, ao contrário, baseada, ainda que minimante, em uma realidade já colocada, em construções simbólicas já existentes e, também, em existências (e resistências) materiais já conhecidas. Como sabemos, nos anos de 1917-1930 já havia centenas de mulheres engajadas nas causas comunistas.

A criação dos cartazes, assim, não era arbitrária. Em contraposição, sabemos que uma representação é sempre um ideal, então, mesmo essas revolucionárias claramente não se comportavam exatamente como o retratado nos cartazes. Além disso, as milhares de mulheres que não se enquadravam nesse grupo encontravam-se representadas nos pôsteres, 
metonimizadas no estereótipo de revolucionária, o que nos indica uma busca de hegemonia para construções simbólicas não hegemônicas. Podemos quanto a isso nos utilizar de uma formulação de Chartier, quando ele afirma que "uma representação tenta fazer presente algo que está ausente” (CHARTIER, 2010.) Essa afirmação nos possibilita acrescentar a seguinte dedução: a mulher soviética (em maioria) não se apresentava de determinados modos específicos, mas o Partido desejava que ela se apresentasse com tais modos específicos; logo, o Partido evocava a imagem dessa mulher com esses modos específicos em sua propaganda visual. Se não era arbitrário, também não podemos dizer que a criação era totalmente controlada, posto que seus produtores da mesma forma estavam condicionados ao contexto histórico dos mesmos. Assim, ainda que na tentativa de responder e combater a lógica dominante, igualmente não conseguiam escapar totalmente dela. Era daí que surgiam os discursos e práticas partidárias (e sociais).

Nas propagandas e também nos outros meios de representação, buscamos, assim, padrões e deslizes que nos parecem sinalizar escolhas menos conscientes e carregadas de valores e juízos legítimos e ativos naquele momento histórico (muitas vezes, dão-se, inclusive, em contradição com a agenda consciente dos produtores). Por fim, entendemos, dessa forma, que os limites quanto à emancipação feminina nas imagens estudadas podem ser considerados, em algum grau, os limites da própria sociedade.

A tentativa de explicação é a de que a mulher "construída" pelos cartazes - que a expunham em primeiro ou segundo plano - não correspondia aos padrões vigentes no sistema anterior e ainda estava em construção no novo sistema, contrapondo-se ao primeiro a fim de construir uma nova imagem; uma nova mulher.

Um dos indícios de que essa transgressão ocorreu está na própria arte concebida pelos cartazes: a mulher celibatária representada pelo PC não obedece à dominação do homem na obra artística. Como afirma a historiadora da arte Bonnet (BONNET, 2008), em sua análise sobre a questão do gênero, a arte sempre foi ditada pelos homens - em geral era ele que decidia seus valores estéticos, modelos, padrões de excelência ${ }^{x i}$. Esses, então, eram apenas vistos pelos olhos do homem, sendo o lugar da mulher no mundo artístico sempre o de "ser observado". Temos, ao contrário, representadas nos pôsteres em geral, mulheres que não estão em um lugar de objeto (sexual ou não, frequentemente marcado pela fragilidade e submissão - religiosa e paternalista -, ocupando o espaço caseiro da domus), mas sim, de sujeito (agente, forte, possuidor de potência, ocupando o espaço público da ágora); sujeito 
esse que seria equivalente, então, ao sujeito masculino, isso é, objetivava-se constituir a igualdade entre os gêneros. Tal transgressão foi possível graças aos próprios objetivos de construir e representar uma mulher adentrada em uma ideologia distinta do legitimado, convergida ao fato de os políticos, pressionados muitas vezes pela ala feminina partidária impulsionada pelo Jenotdel - terem conseguido ultrapassar as barreiras do legítimo, possibilitando, ainda, a legitimação dessas novas formas pela população.

Acreditamos, assim, que, na tentativa de investigar os limites da proposta de igualdade de gênero, por meio dos cartazes soviéticos que retratam as mulheres, suas funções sociais e suas relações para com os outros sujeitos, em convergência com outros tipos de políticas do PC, tal como políticas de formação e as formulações legais, pode-se compreender, em alguma medida, os lugares que o Partido Comunista designava como sendo próprios das mulheres e em que medida foi possível a transgressão, em lugar da reprodução, de novos parâmetros sociais e conceituais. Tendo apresentado o contexto e as problemáticas relativas à questão, apresentaremos no próximo subitem algumas das conclusões observadas no debruçar da análise nos cartazes soviéticos que giram em torno da representação feminina.

\section{A nova mulher e as velhas ideologias: o feminino re-idealizado}

As contradições e permanências inerentes ao processo de transformação são percebidas nas novas estruturas e políticas sociais criadas; nas leis e decretos; nas posturas dos indivíduos; e, por fim, também na propaganda política, da qual o cartaz é uma de suas faces mais públicas.

Um dos exemplos passíveis de serem citados refere-se à transformação do lugar feminino - que em tese deixa de pertencer ao âmbito doméstico, para pertencer ao público, político, econômico. A política aplicada era, de fato, revolucionária para a época: tornar as tarefas historicamente delegadas às mulheres - como lavar roupas, cuidar das crianças, cozinhar - responsabilidade do Estado. Criou-se, então, lavanderias, creches, cafeterias e restaurantes, todos públicos e gratuitos, para que a mulher pudesse ver-se livre e realizar outras atividades, como o trabalho fabril ou a militância política. Porém, houve aí uma contradição, com duas faces principais. A primeira é que somente mulheres trabalhavam nessas estruturas. Ainda que tenha sido um passo revolucionário considerar as históricas atividades enquanto trabalho, esse foi o limite atingido pelos sujeitos históricos daquele 
momento. A segunda face dessa contradição gira em torno da representação. Como pode-se perceber no cartaz abaixo (Figura $n^{\circ} 1$ ), era a mulher que era entendida como responsável pela criança e pelas tarefas domésticas. Como mostramos em um artigo anterior (SENNA, 2014), só é percebida a presença da figura paterna ao lado da criança em dois casos: se com a mãe, representando a família; se a temática é relacionada a esportes - e ambos só são vistos após o período stalinista. 
Figura 1: "Todas vocês, babi, deveriam saber como criar uma criança"

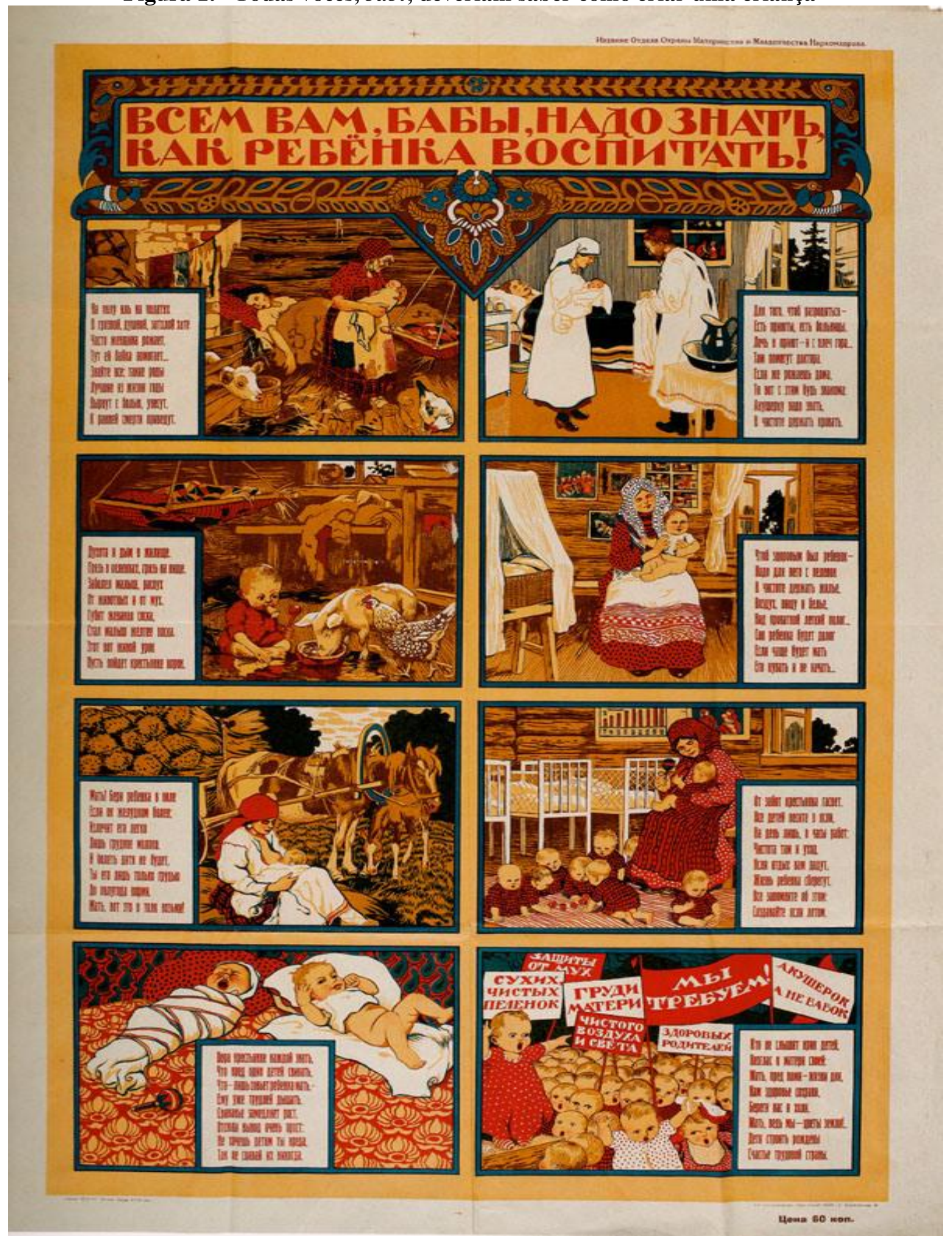

Fonte: Komorov, Alexei, 1925.

Tradução $o^{x i i}$ :

Página $\mid 116$

História e Cultura, Franca, v. 6, n. 1, p. 103-125, mar. 2017. 
Primeiro quadro (coluna 1, linha 1)

Muitas vezes uma mulher dá a luz

No chão ou na cama,

em uma cabana suja, abafada e mofada.

Em seguida, a $b a b k a^{x i i i}$ ajuda.

Saiba que os partos assim

vão tirar com dor

os melhores anos da vida

e na morte prematura resultarão.

Segundo quadro (coluna 2, linha 1)

Para dar a luz,

há hospitais, há abrigos.

E no abrigo acabam as preocupações.

Lá os médicos ajudarão.

Já se der a luz em casa,

saiba o seguinte:

tem que chamar a enfermeira especializada,

e manter a casa limpa.

Terceiro quadro (coluna 1, linha 2)

Com a fumaça e o abafamento dentro da casa,

a sujeira na fralda e na comida,

os animais e as moscas,

o bebê adoeceu, inchou.

A chupeta toda mastigada faz mal

o bebê ficou amarelo como cera.

É uma lição viva.

Que a camponesa ${ }^{\text {xiv }}$ aprenda no futuro.

Quarto quadro (coluna 2, linha 2)

Para que a criança seja saudável, necessita de berço,

ar, roupas e moradia

e de que se mantenha uma casa limpa,

Sobre o bercinho, um dossel levinho.

O sono da criança será longo

se com mais frequência irá a mãe

banhá-la ao invés de balançar.

Quinto quadro (coluna 3, linha 1)

Mãe! Leve a criança ao campo.

Se ela está doente do estômago,

apenas o leite materno

vai curar facilmente.

A criança não vai ficar doente

se apenas com o peito

até seis meses o amamente.

Mãe, leve isso em consideração.

Sexto quadro (coluna 3, linha 2)

Com as preocupações, a camponesa se desgasta.

História e Cultura, Franca, v. 6, n. 1, p. 103-125, mar. 2017. 
Levem as crianças para a creche

por uma vez apenas, nas horas de trabalho

Lá tem limpeza e cuidados.

Creches lhes darão descanso

e preservarão a vida da criança.

Todos lembrem-se disso:

de criar novas creches de verão.

Sétimo quadro (coluna 4, linha 1)

Está na hora de toda camponesa saber que só mal faz enrolar as crianças, que basta uma mãe enrolar a criança e para ela já fica mais difícil respirar.

Enrolação atrasa o crescimento

Daí a conclusão muito simples:

se você não quer fazer mal às crianças, então, nunca as embrulhe

Oitavo quadro (coluna 5, linha 2)

Quem não escuta os gritos das crianças

apela para sua mãe.

Mãe, diante de nós estão os dias da vida.

Para nós, preserve a nossa saúde.

Proteja e cuide bem, mãe

pois nós somos as flores da terra.

As crianças foram nascidas para construir

a felicidade do país trabalhador.

Nas placas, lê-se:

Proteção das moscas!

Fraldas secas e limpas!

Peito da mãe!

Ar limpo e luz!

Nós exigimos!

Pais saudáveis!

Enfermeiras especializadas, e não parteiras amadoras!

Continuou a se promover, assim, uma lógica de um desenvolvimento anterior à época em que as mulheres foram chamadas de forma massificada a adentrar ao mercado de trabalho - tanto em relação à economia, dado o pragmatismo tecnicista que corroborava seu papel realizado em um sistema que há milênios não existia, quanto em relação à cultura, já que se promoveu, com tais políticas partidárias, ideias da relação biológica e natural que a mulher teria com as tarefas de cunho doméstico, postura essa profundamente anistórica. Esse aspecto não é apenas visto na materialidade do trabalho não dividido nas cozinhas e refeitórios públicos. 
Ainda assim, houve espaço, no entanto, para transgressões quanto ao papel feminino. Se, nos cartazes, é visível que o fato de constar uma representação feminina como composição da sociedade, ao mundo do trabalho ou (o que era mais comum) à família, esse fato não deve ser naturalizado e entendido como normal: essa é uma diferença crucial, que nos diz sobre os interesses do PC em relação à mulher e sobre o papel dos próprios cartazes. Partindo da premissa de que "A arte não é um espelho para refletir o mundo, mas um martelo para forjá-lo", como escreveu Maiakóvski, os cartazes, que por mais propagandísticos e pedagógicos que fossem, preservavam seu aspecto artístico, tinham a possibilidade de apresentar ao espectador uma realidade ainda não vivenciada. No caso da representação feminina nos cartazes, entendemos que Estado, até 1931, aproveitou essa possibilidade para auxiliar no processo emancipatório no sentido de inseri-las na sociedade e, em alguns graus, igualá-las aos homens. Desse modo, Bonnell, usufruindo do contexto de interpretação da arte política, por meio de repertórios culturais, atenta para a imagem da mulher como ajudante de ferreiro, que pode ser observada, entre tantos outros cartazes, na Figura n'2 (abaixo)

Figura 2: "Nós destruímos o nosso inimigo com armas, vamos fazer o pão com o trabalho Todos ao trabalho, camaradas!".

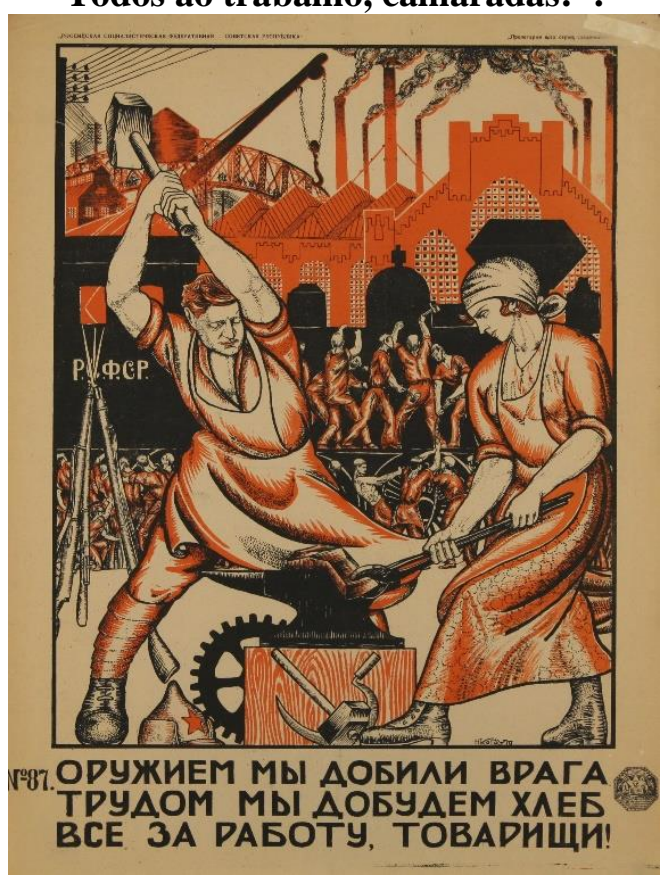

Fonte: Nikolai Kogout, 1920. Disponível em: Granger Collection/Alinari Archives Acesso em $18 / 02 / 2016$ 
Esse lugar, diz Bonnell, era excessivamente estranho ao espectador da época (BONNELL: 1997, p.14). Fosse na cidade ou no campo, não era habitual que as mulheres se envolvessem nesse tipo de atividade. Questionamos, então: qual tipo de transformação, então, um estranhamento desse pode causar? Alguns contemporâneos soviéticos, reflete Bonnell, rejeitariam tal imagem como absurdo. Outros, poderiam procurar inserir a mesma em simbolismos da cultura popular ou mitologia clássica. Como coloca a autora, não é possível saber ao certo, dado que não há documentação histórica relacionada a essa recepção. Porém, o que importa aqui é que o governo insistiu em colocar (ou aceitar) nos cartazes as mulheres em lugares estranhos aos que ela ocupava, colocação essa que, não menos importante, era conjugada com outros mecanismos que buscavam inserir a mulher na sociedade, nos ambientes de trabalho e em demais lugares que a ela não pertenciam. Apesar das reações negativas, após algum tempo, em algum grau, essa Nova Mulher deixou de ser tão estranha quanto antes - fosse nos cartazes, fosse na realidade.

Podemos inferir como outra inovação artística o fato de a mulher aparecer em diversos cartazes sozinha ou com outras mulheres, mas sem figuras masculinas. Artisticamente, esse é um ponto transgressor à época. Como coloca Griselda Pollock (POLLOCK, 2011), era corrente nos países capitalistas em geral não compreender a mulher no lugar do trabalho, da vida pública, da cidade (locais que são representados abarcando as mulheres nos cartazes). Apesar de a mulher ter o seu sentido muito bem delineado - a trabalhadora, ou a revolucionária, ou mesmo, a mãe - rompia com esquemas representativos clássicos que limitavam grande parte das obras, como a mulher como símbolo sexual ou como submissa. Trabalhadora, revolucionária ou mãe, a mulher nos cartazes soviéticos era ativa, por vezes, protagonista, e continha nela a potência para transformar. Socialmente, isso dizia respeito da sua potencialidade quanto a realizar tarefas técnicas ou políticas. A colocação da mulher na política foi também um grande passo dado pela sociedade soviética, frente há séculos de silenciamento da voz feminina nesse campo. $\mathrm{O}$ aspecto político também não é natural ao ser humano. O silenciamento que a mulher constantemente viveu quanto a ele iniciou-se apenas com a sociedade de classes (REED, 1969). 
Ao considerar que metade da população deveria, então, participar da vida pública, com poder de voto e de ser eleita, o PC insere-se na contra-mão do histórico silenciamento feminino na política. Ter criado um departamento para lidar com esse fenômeno histórico foi, talvez, um dos seus maiores feitos. Feito esse que teve, de fato, resultados consideráveis, como vemos por exemplo quanto ao número crescente de delegadas nos congressos femininos. Muitas mulheres lutavam por uma sociedade melhor, delegadas provindas da população saíam de suas aldeias para falar o que acreditavam, saíam de suas cidades mais afastadas para argumentar por melhores condições de vida. Contudo, observamos que as mesmas mulheres militantes do PC que lideravam multidões, jamais conseguiram de fato liderar o próprio Partido. A direção partidária fora sempre, majoritariamente, compreendida por homens.

O homem, como ser genérico, suas decisões apenas poderiam ser para o bem de toda a sociedade - desconsiderando que toda resposta só provém da experiência cotidiana e que nenhum bolchevique homem jamais pôde se colocar, de fato, no lugar de uma mulher fosse ela líder partidária ou trabalhadora.

\section{À guisa de conclusão}

Tendo em vista a reflexão produzida, duas principais conclusões vêm à tona. A primeira delas tange a uma transgressão que conseguiu não apenas realizar-se como tal, mas fincar-se na cultura russa. A partir do estranhamento - isso é, a exposição de mulheres em lugares e práticas antes não comuns - conseguiu-se de fato consolidar-se um novo tipo feminino na sociedade. Seja pelo motivo pragmático, de este aspecto servir diretamente ao Estado, seja por questões outras, a consequência que mais resistiu ao tempo - inclusive à própria queda da União Soviética - é a presença feminina no mercado de trabalho, em funções historicamente masculinas. Essa não apenas perfurou o tempo histórico daquele momento - em que, em sua maioria, não se tinha mulheres em ambientes de trabalho que não o doméstico - como ultrapassou as funções entendidas como possíveis às mulheres. Assim, fez-se comum na URSS mulheres maquinistas, motoristas de tratores, engenheiras, operárias de fábricas, professoras de ensino superior, militares - cumprindo papel crucial na Segunda Guerra Mundial - e até astronautas - tendo, inclusive, muitos cartazes de 
propaganda com o rosto da primeira dessas a ser enviada para o espaço: Valentina Terechkova, em 1962.

Houve, de fato, transformações profundas e conquistas importantíssimas. As mulheres conquistaram um espaço sem precedentes em diversos âmbitos da sociedade. No entanto, ao que parece, esse espaço era limitado, principalmente, às questões que o próprio Partido colocava como sendo próprias das mulheres. A maternidade, a reprodução da vida, o casamento, e, mais originalmente, o mercado de trabalho, eram os aspectos principais sobre os quais as delegadas do Jenotdel discutiam e, também, sobre os quais o Partido deixava aparecer a representação feminina. Isso talvez, enfim, tenha ocorrido por, Partido e sociedade, homens e mulheres, não terem conseguido superar uma inverdade que até à atualidade se faz presente: o homem representar o ser genérico. Esse aspecto corrobora o cenário histórico-filosófico em que os discursos que assujeitam o indivíduo remetem-se exclusivamente ao homem adulto dito normal. Das muitas obras analisadas, pudemos observar que a mulher aparecia em apenas dois casos: o primeiro, quando se tratava de questões colocadas como próprias de seu gênero; o segundo, quando estava a representar, com o homem, a família ou a sociedade. Nesse último caso, porém, nunca foi encontrado um pôster do período estudado em que a mulher aparecesse, plena, como cidadã representativa de toda a sociedade, sem que ao seu lado houvesse um homem. Entretanto, como vemos na figura 3 (abaixo) e em muitas outras, o homem cumpriu plenamente essa missão. 
Figura 3: "Viva ao Outubro Internacional!".

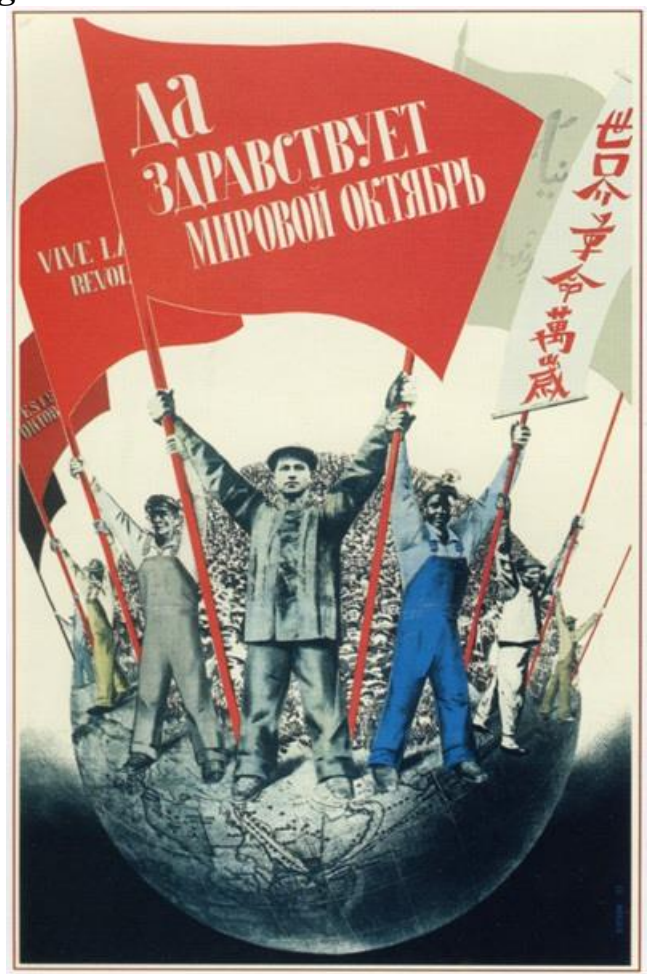

Fonte: Gustav Klutsis, 1933. Disponível em: http://www.alamy.com/stock-photo-long-live-worldoctober!-1933-artist-klutsis-gustav-1895-1938-60422642.htm. Acesso em 20/07/2016

\section{Referências:}

ANDRADE, Joana El-Jaick. "O feminismo marxista e a demanda pela socialização do trabalho doméstico e do cuidado com as crianças." Rev. Bras. Ciênc. Polít., Brasília , n. 18, p. 265-300, Dec. 2015 . Disponível em:

$<$ http://www.scielo.br/scielo.php?script=sci_arttext\&pid=S0103-

33522015000400265\&lng=en\&nrm=iso>. Acesso em 06 Dez. 2016.

BADINTER, Elizabeth. Um amor conquistado: o mito do amor materno. Rio de Janeiro: Nova Fronteira, 1980.

BONNELL, Victoria. Iconography of Power: Soviet Political Posters under Lenin and Stalin. Berkeley: California: University of California Press, 1997.

BONNET, Marie Jo. Résistances de "l'objet-dard". Contestations des signes du masculin dans l'art du xxe siècle. Edição Online,2008. Disponível em <www.lrdb.fr>. Acesso em 20 dez. 2015.

CHARTIER, Roger. Defesa e ilustração da noção de representação. Disponibilizado pela Universidade Federal do Rio Grande do Sul em:

<http://www.ufrgs.br/gthistoriaculturalrs/nocaoderepresentacao.pdf > . Acesso em nov. 2014.

GULDBERG, Jorn. Socialist Realism as Institutional Practice: Observations on the Interpretation of the Works of Art of the Stalin Period in The Culture of Stalin Period, p. 149-177. Londres: Palgrave Macmillan UK, 1990.

HOBSBAWM, Eric. A Era dos Impérios. Rio de Janeiro: Paz e Terra, 1988. . Sobre História. São Paulo: Companhia das Letras, 1997. 
KOLLONTAI, Alexandra. A nova mulher e a moral sexual [1918] Rio de Janeiro: Global, 1978.

Autobiografia de uma mulher sexualmente emancipada. São Paulo: Editora

Sundermann, 2007.

LENIN, Vladimir. As tarefas do proletariado em nossa Revolução, escrito de 10 a 23 de abril de 1917, publicado em brochura em setembro do mesmo ano. Obras escolhidas, T; II, p. 30, Edições em línguas estrangeiras, Moscou: [s.e.], 1947.

NOVACK, George. O desenvolvimento desigual e combinado na história. São Paulo: Sundermann, 2008.

PERROT, Michelle; BRESCIANI, Stella. Os excluídos da história: operários, mulheres e prisioneiros. São Paulo: Paz e Terra, 1988.

POLLOCK, G.A modernidade e os espaços da feminilidade in Gênero, cultura visual e performance - Antologia Crítica (org. Ana Gabriela Macedo; Francesa Rayner). Edições Minho: Famalicão, 2011

REED, Evelyn. . Mulher e Família: Uma análise Histórica. 1969. Disponível em: <https://www.marxists.org/portugues/reed-evelyn/1969/05/09.htm> Acesso em mar. 2015. SENNA, Thaiz. A nova mulher e os limites das representações femininas nos pôsteres soviéticos (1917-1930) in Anais do VII Simpósio de História Cultural. On-line. São Paulo, 2014.

WOOD, Elizabeth. The Baba and the Comrade: Gender and Politics in Revolutionary Russia.: Bloomington: Indiana University Press, 1997.

Notas:

i O termo celibatária é usado na obra de Kollontai (1978) no sentido do tipo feminino que não mais pode contar com a força dos homens para sobreviver, apenas com as suas próprias. Não conseguimos acesso à edição russa, mas todas as edições brasileiras a que tivemos acesso usam o mesmo termo que se relaciona ao sentido de "Que, ou aquele que não se casou". O termo correspondente em russo seria nezamújniaia jénschina.

ii Kollontai considera aqui essas duas possibilidades em relação à capacidade financeira da mulher ao trabalhar fora de casa. Isso não significa, contudo, que a nova mulher era livre para não casar e ter filhos diante das pressões socioculturais, ainda arraigadas às tradições históricas e religiosas

iii Tal hipótese foi defendida na dissertação de nossa autoria, pelo Programa de Pós-graduação em História da Universidade do Estado do Rio de Janeiro, em março de 2016.

iv A liberação para a participação na vida política ativa, na direção do trabalho, na vida cultural e intelectual era um problema colocado tanto para homens quanto para mulheres, dada a quantidade de horas trabalhadas nas fábricas de demais estabelecimentos. Esse problema por um lado na questão da redução da jornada de trabalho, já que se trabalhando menos, haveria mais tempo para realizar as outras atividades. Tal reivindicação fazia-se presente na Rússia desde o manifesto de 1905 e tendo sido abordada também no Governo Provisório, após a queda do tsar. Até 1929, a jornada de 8 horas por dia e 6 dias por semana vigora Ainda que esse problema perpasse ambos os gêneros, é sabido que as condições femininas são ainda piores, dadas as outras jornadas (trabalhos domésticos, cuidados com os filhos) que as sociedades lhe impõem.

${ }^{v}$ Era uma prática tradicional principalmente no campo presentear os noivos com chicotes, para que eles castigassem suas esposas

${ }^{\text {vi }}$ Perrot nos conta que em alguns momentos da história, em determinados lugares da Europa medieval, as mulheres praticavam ofícios profissionais dentro de casa e o ofício doméstico era, então, do marido. Ainda assim, aponta a autora o marido era considerado o chefe da casa, corroborando as práticas opressoras da suposta superioridade (PERROT, 1988, p.189); Já o lugar de mãe é uma pressão mais moderna, como trabalharemos com Badinter (1980), embora a paternidade não tenha tido lugar central na história.

vii Como nos mostra a antropóloga Evelyn Reed, ainda que, nas sociedades primitivas, anteriores às sociedades de classes, a mulher fosse responsável por tais tarefas, ela era completamente livre, nunca tendo

Página | 124

História e Cultura, Franca, v. 6, n. 1, p. 103-125, mar. 2017. 
sido obrigada a realizar tais tarefas, posto que era um acordo, dado por uma divisão do trabalho em prol de conseguir alimentos escassos, garantindo a sobrevivência de toda a comunidade

viii Enunciado de um cartaz de propaganda soviético (1931): “Abaixo à escravidão na cozinha! Dê-nos uma nova existência!" Chegal, Grigóri, 1931.

ix Essa teoria diz respeito à necessidade da revolução continuar avançando, inclusive para os outros países, a fim de que houvesse uma internacionalização do socialismo. Ela se contrasta à teoria stalinista do "socialismo em um só país", já que indica a impossibilidade de que haver, seja em determinada etapa, seja em período indefinido, uma organização socialista ilhada diante de todas as outras forças, capitalistas.

${ }^{x}$ Aqui nos referimos principalmente aos primeiros anos da RSFSR, contexto o qual transformou de fato aspectos estruturais da sociedade, de forma libertária e progressiva. Com o tempo, principalmente após a introdução do stalinismo, é comum que os mesmos meios que antes serviram, mesmo que com limitações, para libertar (como os cartazes soviéticas e muitos outros tipos de arte) viram meios para consolidar o stalinismo (como o movimento do realismo soviético nas artes) e, futuramente, a própria reconversão ao capitalismo.

xi Necessário marcar algumas exceções, tal como as poetisas russas Maria Tsvetaiéva, Anna Akhmátova e Zianída Serebriakóva, prestigiada pintora modernista. Tal como pintoras já citadas, cuja carreira se encontra nas primeiras duas décadas do século XX. Por um lado, isso demonstra que a representação das mulheres nos cartazes estava em convergência com seu próprio tempo histórico; por outro, porém, o ultrapassava: superava não só as representações hegemônicas; não partia somente de mulheres a arte que transgrediria o papel feminino; tangia a questões de toda a sociedade, em âmbitos políticos, econômicos e culturais, e não apenas emocional e pessoal, como era mais comum se ver na arte anterior.

xii Tradução nossa, em conjunto da professora Ekaterina Américo e realizada com apoio do LABESTRADUFF. Dois apontamentos são necessários sobre nossa tradução: o cartaz é feito em forma de versos, muitas vezes rimados, e essas rimas não foram preservadas na tradução, apenas o sentido;

os versos não estão na ordem original, para possibilitar melhor entendimento (já que a língua russa é menos fluida, muito do sentido ficaria confuso se fosse obedecida a ordem original).

xiii Contração de Bábushka, avó, babka pode significar "vovó" ou parteiras não profissionais, como é o caso no cartaz.

xiv Observa-se que o termo aqui traduzido é o krestianke, que significa camponesa em seu sentido formal e não no informal-inferiorizante, $b a b a$ e constará, portanto, traduzido como camponesa, quando do seu aparecimento.

Artigo recebido 01 de dezembro de 2016 e aprovado em 28 de fevereiro de 2017. 